International Journal of Agriculture, Environment and Bioresearch

Vol. 5, No. 01; 2020

ISSN: $2456-8643$

\title{
DETERMINATION OF ENROFLOXACIN RESIDUE IN CHICKEN EGGS USING LIQUID CHROMATOGRAPHY - MASS SPECTROMETRY METHOD
}

\author{
Sadik Heta ${ }^{1}$, Fatmira Shehu ${ }^{2}$ and Drita Bajraktari ${ }^{3}$ \\ ${ }^{1} \mathrm{PhD}$ Candidate at the Faculty of Veterinary Medicine - Albania,Food and Veterinary Agency - Kosovo, Industrial \\ Zone, Pristina 10000 \\ ${ }^{2}$ Faculty of Veterinary Medicine, Agricultural University of Tirana ,Koder Kamez, sh1, Tirana 1000 Albania \\ ${ }^{3}$ Food and Veterinary Laboratory - FVA Kosovo, Industrial Zone, Pristina 10000
}

https://doi.org/10.35410/IJAEB.2020.5483

\begin{abstract}
The number of poultry farms in Kosovo is constantly increasing and the need to prevent infectious bacterial infections in poultry has led to the use of antibacterial preparations, which in addition to the beneficial effects of combating these diseases, also poses risk to public health. The purpose of this study was to confirm the presence or absence of enrofloxacin residues in 8 egg samples, after analyzing 180 eggs samples collected at commercial farms in Kosovo with the Elisa Test. The confirmation method used was the Liquid Chromatography Mass Spectrometry. 2 of 8 samples resulted with presence of enrofloxacin residues. The findings suggest that illegal use of enrofloxacine in chicken farms is present and highlight the fact that chicken farmers were using antibiotics as a promoter of egg production and body weight and to reduce the incidence of infectious diseases. Both the tests are performed at the Kosovo Food and Veterinary Laboratory. The testing was performed according to the Commission Decision 2002/657/EC
\end{abstract}

Keywords: Enrofloxacin, Eggs, Liquid Chromatography Mass Spectrometry .

\section{INTRODUCTION}

The discovery of antibiotics was one of the greatest achievements in the history of mankind. Antimicrobials are our most powerful allies in the fight against communicable diseases. Enrofloxacin is widely used in veterinary medicine because of the broad spectrum of activity and high efficacy against Gram-positive and Gram-negative bacteria (M G-Sikorska et al, 2013)

In the frame of food safety, the European Union (EU) has regulated the use of quinolones as veterinary drugs in food-producing animals and has established maximum residue limits (MRLs) of antibiotics in food. According to EU regulations, quinolones, such as ciprofloxacin, enrofloxacin, sarafloxacin and oxolinic acid are "not for use in animals from which eggs are produced for human consumption", which means they are strictly forbidden in rearing laying hens. No MRLs have been stated for them, and eggs and industrially elaborated egg products 
containing quinolone residues at any level must be rejected (European Regulation (EU). No 37/2010, Regulation (EC). No 470/2009, J P Vicenteet al 2019).

To protect the consumer from exposure to residue levels that might constitute a health risk, the European Union has introduced legislation with regard to authorisation of veterinary medicine. The approval of veterinary medicinal products can only occur after an extensive safety and residue evaluation and subsequent registration in Annex I, II or III of Council Regulation 2377/90 (EC 1990) (Mariel G Pikkemaat et al 2007)

Council Directive 96/23 / EC (Council Directive 1996) requires Member States of the European Union to adopt and implement a national waste monitoring plan for specific groups of substances. However, data from the literature and Rapid Alert System for Food and Feed (RASFF) indicated that there were incidents of ENR illegal use in laying hens' therapy (RASF). Accordingly, their residues need to be controlled to verify the compliance of producers and importers with the regulation.

However, inappropriate or abusive use of antibiotics in poultry farms might provoke the transfer and accumulation of their residues in food products. This causes exposure to the consumer to these compounds in low concentrations which may produce toxic reactions and stimulate the emergence of quinolone-resistant pathogens (Pruden A et al 2006, Friedman, M et al 2015). It has been largely proven that eggs from poultry treated with pharmaceutical products contain drug residues, even those laid days to weeks after treatment cessation (J P Vicenteet al 2019) Given the risk of large-scale use of antibiotics in Kosovo, the Ministry of Health of the Republic of Kosovo, is implementing the Strategic Plan for Microbial Resistance, supported by other relevant institutions including the Food and Veterinary Agency as the only institution dealing with the protection of animal health and public health respectively.

In the Report of EFSA 2018, on the results from the monitoring of veterinary medicinal product residues and other substances in live animals and animal product the examination of 4,476 samples of eggs for antimicrobial residues revealed positivity of $8(0.18 \%)$ samples for doxycycline, enrofloxacin, flumechin and sulfadiazine (EFSA 2018).

According to the Commission Decision 2002/657/EC (European Commission, 2002), the confirmation of suspect positive samples must be carried out by mass spectrometry (MS) coupled to adequate chromatographic separation (Shehu F, et al 2018).

\section{MATERIALS AND METHODS}

\subsection{The regions included in the study}

180 egg samples from commercial farms were collected in 7 regions of Kosovo, respectively: Pristina, Prizren, Ferizaj, Peja, Gjilan, Gjakova and Mitrovica. 1 sample is composed of 12 eggs. The number of farms and poultry eggs by regions under study are in Table 1. 
Table 1. The number of farm and poultry eggs by region under study

\begin{tabular}{|l|l|l|l|}
\hline Region & $\begin{array}{l}\text { No } \\
\text { heads }\end{array}$ & $\begin{array}{l}\text { No of poultry } \\
\text { farms }\end{array}$ & $\begin{array}{l}\text { Samples under the } \\
\text { study }\end{array}$ \\
\hline Pristina & 125648 & 25 & $1 \times 12$ \\
\hline Prizren & 125430 & 28 & $2 \times 12$ \\
\hline Ferizaj & 95421 & 15 & $1 \times 12$ \\
\hline Peja & 125478 & 18 & $1 \times 12$ \\
\hline Gjilan & 62541 & 12 & $1 \times 12$ \\
\hline Gjakova & 365214 & 16 & $1 \times 12$ \\
\hline Mitrovica & 75621 & 13 & $1 \times 12$ \\
\hline & 975353 & 127 & $8 \times 12$ \\
\hline
\end{tabular}

The purpose of this method is to identify and quantify enrofloxacin in the egg. Testing is performed using the analytical method of liquid chromatography with mass spectrometer detector (LC-MS).

The observed limits of detection are in accordance with the various MRLs for the four classes of veterinary drugs, and the average recoveries exceed 50\%, thus meeting the requirement for routine analysis (Jin-Lan Sun et al 2012)

\subsection{Reagents and standards used}

Enrofloxacin, True acetonitrile for waste testing, Methanol suitable for byte testing, Formic acid, Phosphoric acid, Dinateriumhydrogen phosfate dihidrat and Citric acid

\subsection{Instrument Parameters}

Optimization of enrofloxacine for the LCMS method was performed for its determination in suspected samples. 
Table 2 LCMS - Operating conditions for egg enrofloxacin testing

\begin{tabular}{|l|l|}
\hline Column & Phenomenex Gemini 150x3.0mm \\
\hline Eluenti A & Methanol me $0.12 \%$ acid formik \\
\hline Eluenti B & $0.1 \%$ Acid formik \\
\hline Time (min) 0 & Eluent B (\%) \\
\hline 0 & 90 \\
\hline 1 & 90 \\
\hline 10 & 20 \\
\hline 20 & 20 \\
\hline 21 & 90 \\
\hline 30 & 90 \\
\hline Injection Volume & $10.0 \mu \mathrm{L}$ \\
\hline Flow & $0.4 \mathrm{ml} / \mathrm{min}$ \\
\hline MS Parameters: & \\
\hline Detection & ESI+MS/MS \\
\hline Polarity & Positive \\
\hline Scan Type & Schedueld MRM \\
\hline Jon suorce & Turbo spray \\
\hline Rezulution & Q1,Q2:unit \\
\hline ISO voltage & $5500 \mathrm{~V}$ \\
\hline Temperature & $150^{\circ} \mathrm{C}$ \\
\hline Gas 1 (N2) & 45 psi \\
\hline Gas 2 (N2) & $55 \mathrm{psi}$ \\
\hline CAD gas & High \\
\hline Curtain gas: & $30 \mathrm{psi}$ \\
\hline
\end{tabular}

\subsection{Sample homogenization (Preparation of egg samples)}

The $100 \mathrm{~g}$ eggs samples were homogenized. then stored at $-20{ }^{\circ} \mathrm{C}$.

\subsection{Extraction}

In $2 \mathrm{~g}$ of homogenized sample, $100 \mu \mathrm{L}$ of internal standard solution and $10 \mathrm{~mL}$ of EMI Buffer were transferred, stirred in vortex for $1 \mathrm{~min}$, and then placed for $10 \mathrm{~min}$ in Shaker at maximum shaking. The mixture was centrifuged for $5 \mathrm{~min}$ at $4000 \mathrm{U} / \mathrm{min}$. The upper aqueous phase (supernatant) was filtered through a filter in a $50 \mathrm{~mL}$ PE-centrifuge tube. The residue was 
extracted with $6 \mathrm{~mL}$ EMI Buffer. The collected filtrate was used for purification in SPE. Cleaning is done with methanol and Evaporates with nitrogen. After this, concentrations in the mixture of acetonitrile and water, mixed / centrifuge and put in vials and put into to autosampler.

\subsection{Purification of sample extract with SPE-colon}

The filtrate collected in PE-centrifuge tubes was washed with $6 \mathrm{~mL}$ Wash solution and dried for 10 min under vacuum. It was diluted with $6 \mathrm{~mL}$ of methanol and the collected filtrate was placed in PE-centrifuge tubes and then subjected to drying in a nitrogen evaporator at $70^{\circ} \mathrm{C}$.

\subsection{Liquid Chromatography-Mass Spectrometry}

After processing the samples we started the analysis in LC immediately. If the analysis was not possible on the same day, then the samples were stored at $-20^{\circ} \mathrm{C}$. Before the instrument started, we made sure that all solvents, wash lines, columns, and detectors were about 5 min in advance.

HPLC parameters were set: Eluent A: formic acid in water LC-MS $0.2 \%$ and Eluent B: formic acid in acetonitrile LC-MS $0.2 \%$. Flow: $0.35 \mathrm{~mL} / \mathrm{min}$. Column temperature: $25^{\circ} \mathrm{C}$. Injection volume: $10 \mu \mathrm{l}$. Injection temperature $10^{\circ} \mathrm{C}$ and MS / MS parameters set. 
International Journal of Agriculture, Environment and Bioresearch

Vol. 5, No. 01; 2020

ISSN: $2456-8643$

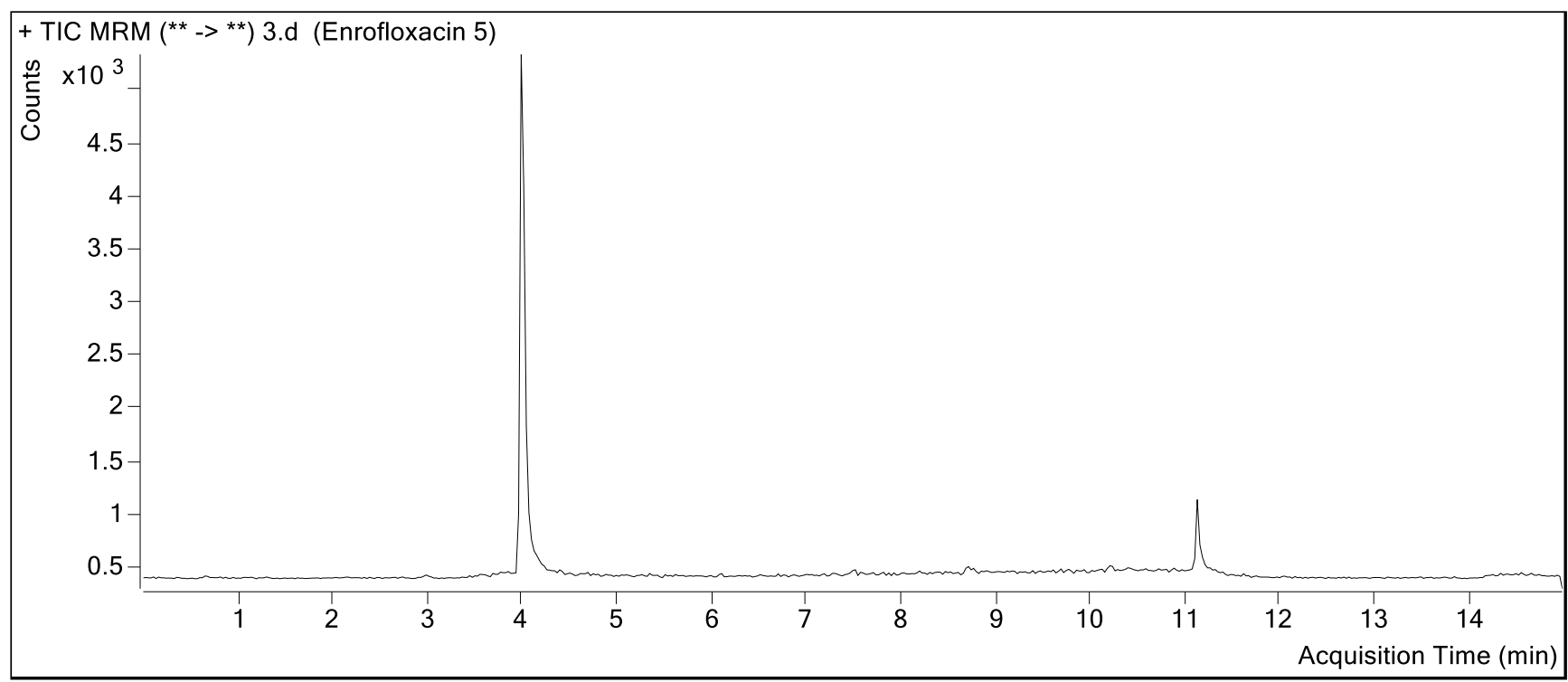

Figure 1. Chromatogram of enrofloxacine in spike sample $5 \mathrm{ug} / \mathrm{kg}$

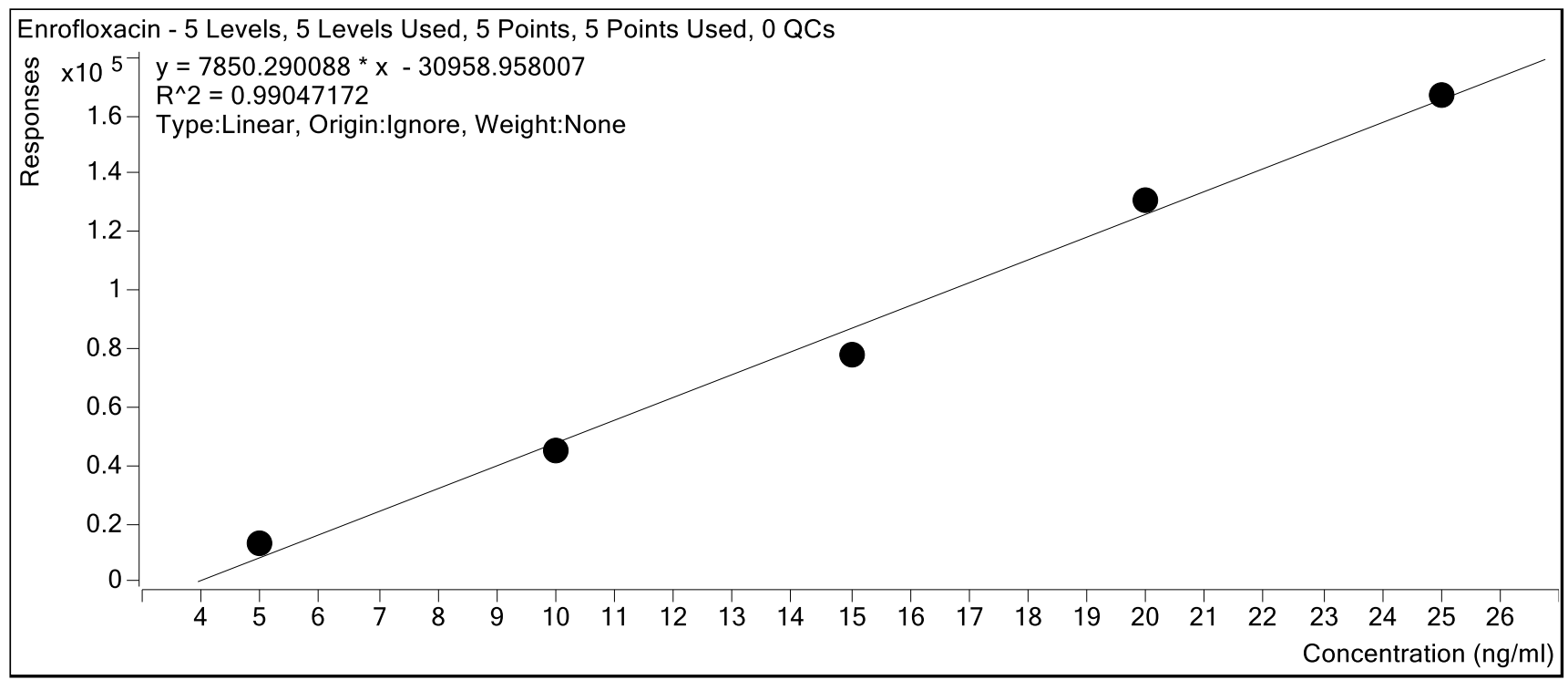

Figure 2. Calibration curve with spiking samples $(5,10,15,20.25 \mathrm{ug} / \mathrm{kg})$ 


\section{RESULTS AND DISCUSSIONS}

The basis of this study was the determination of enrofloxacin residues in eggs at commercial farms in Kosovo. All samples were taken as part of the annual plan for control and monitoring of antibiotics in chicken eggs, compiled by the competent authority - the Kosovo Food and Veterinary Agency.

The high performance liquid chromatographic method has been used to determine the maximum residual limit of enrofloxacin in the egg as an accurate and reliable method. The 8 from 180 egg samples were resulted suspected using Elisa test, and these 8 egg samples were analysed for confirmation. From these 8 samples we found that in 2 of them are present the enrfloxacin residues (Fig. 3).

The analytical quality was evaluated by the guidelines of the EU Commission Decision 2002/657/EC (specificity, calibration range, linearity, trueness, precision, decision limit, detection capability, robustness, and stability).

According to this study, it turns out that chicken farmers were using antibiotics as a promoter of egg production and body weight gain and in some cases to reduce the incidence of infectious diseases.

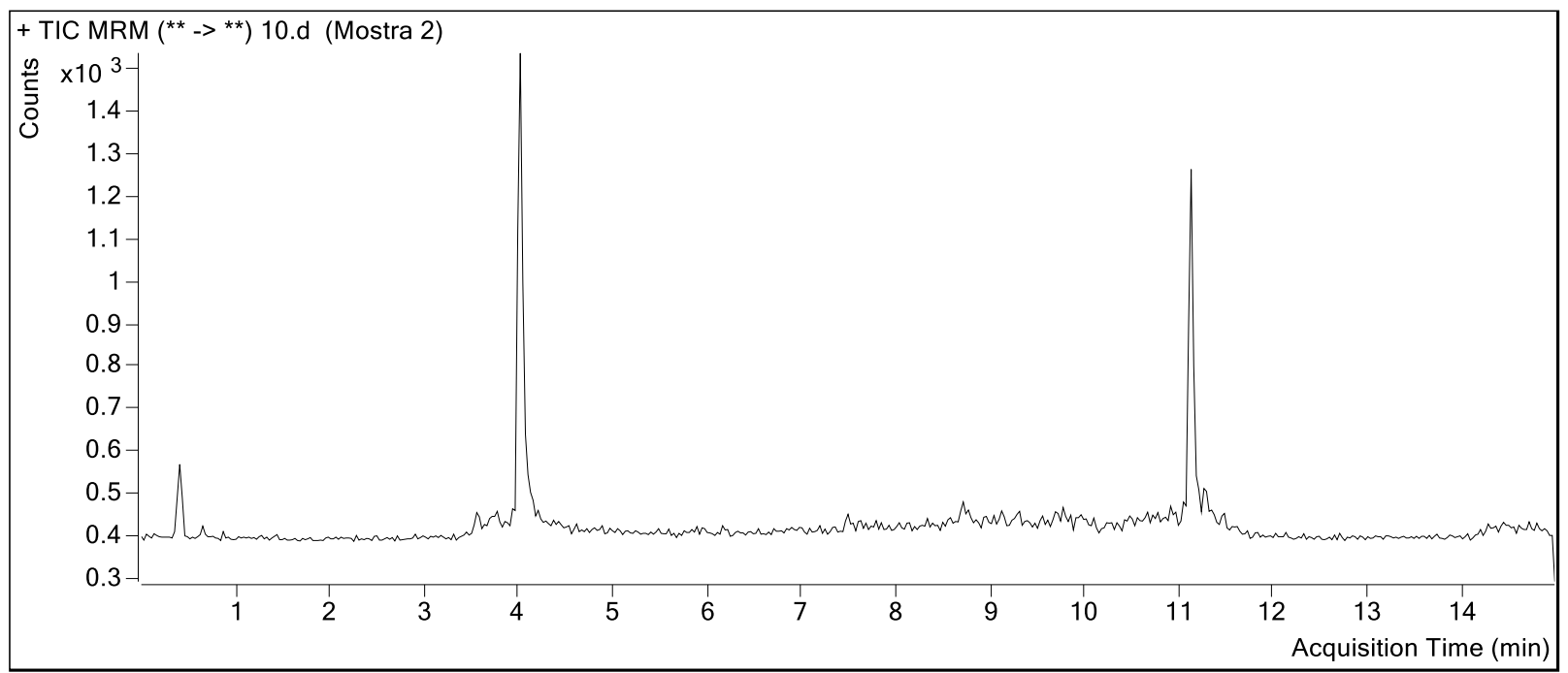

Figure 3. Sample chromatogram with MRL concentration 


\section{REFERENCES}

- Commission Decision 2002/657/EC (Commission Decision 2002)

- EFSA, 2018: Report for 2016 on the results from the monitoring of veterinary medicinal product residues and other substances in live animals and animal products. https://efsa.onlinelibrary. wiley.com/doi/epdf/10.2903/sp.efsa. 2018.EN-1358.

- European Commission. Commission Regulation (EU). No 37/2010 of 22 December 2009 on pharmacologically active substances and their classification regarding maximum residue limits in foodstuffs of animal origin. OJEC 2002, L15, 1-72.

- European Commision. Regulation (EC). No 470/2009 of the European Parliament and of the Council of 6 May 2009 laying down Community procedures for the establishment of residue limits of pharmacologically active substances in foodstuffs of animal origin, repealing Council Regulation (EEC) No 2377/90 and amending Directive 2001/82/EC of the European Parliament and of the Council and Regulation (EC) No 726/2004 of the European Parliament and of the Council. OJEC 2009, L152, 11-23.

- F Shehu, S Kola, E Marku, B Bijo 2018. Detection of chloramphenicol residues in milk samples using ELISA and LC/MS-MS. Ejons, International Journal on Mathematik, Ingineering and Natural Sciences. Year 2018 (2) Vol 3. ISSN 26024136

- J P Vicente, D G Ferrer, P Mishra, J A Chiva, A Durgbanshi, S C Broch, D Bose and J E Romero. (2019). Procedure for the Screening of Eggs and Egg Products to Detect Oxolonic Acid, Ciprofloxacin, Enrofloxacin, and Sarafloxacin Using Micellar Liquid Chromatography. Antibiotics 2019, 8, 226; doi:10.3390/antibiotics8040226.

- Jin-Lan Sun, Chang Liu, Yue Song, Jian-Zhong Li. (2012) Screening 36 Veterinary Drugs in Animal Origin Food by LC/MS/MS , Combinet with Modified QuEChERS Method. Aligent Beijing Technologies Co.,Ltd., Shanghai, 200131 China

- Mariel G Pikkemaat, Patrick P J Mulder, J.W. Alexander Elferink, Michel Nielen, Angela de Cocq, et al.. (2007) An improved microbial screening assay for the detection of quinolone residues in egg and poultry muscle. Food Additives and Contaminants, , 24 (08), Co., Ltd., spp. 842-850.

- $\quad$ M G-Sikorska, A Posyniak, A Gajda, T Błądek. (2013), Determinaton of enrofloxacin and ciprofloxacin in albumin and freeze-dried-eggs by liquid chromatography with fluorescence detection. Bull Vet Inst Pulawy 57, 351-355, DOI: 10.2478/bvip-20130061

- Pruden A, Pei R.T, Storteboom H, Carlson K.H. (2006) Antibiotic resistance genes as emerging contaminants: Studies in northern Colorado. Environ. Sci. Technol., 40, 74457450.

- Rapid Alert System for Food and Feed (RASFF) Portal: https:// webgate. ec.europa. eu/ rasffwindow/ portal/index.cfm? event= notification Detail \& NOTIF _ REFERENCE $=2010.1220$ 
International Journal of Agriculture, Environment and Bioresearch

Vol. 5, No. 01; 2020

ISSN: $2456-8643$

- Friedman, M. Antibiotic-resistant bacteria: (2015) Prevalence in food and inactivation by food-compatible compounds and plant extracts. J. Agric. Food Chem., 63, 38053822 . 